\title{
Caso de Polícia: Reflexões sobre a Questão Social e a Primeira República
}

\section{Police case: reflections on social issues and the First Republic}

ISSN

1809-9475

\author{
Mônica Santos Barison ${ }^{1}$
}

Palavras-chave:

Questão social

Primeira república

Particularidades

históricas

\section{Resumo}

Consideramos que a produção do debate acerca da questão social, objeto de intervenção do assistente social, deve reconhecer como objetivo, dentre outros, compreender as especificidades da formação histórica da sociedade brasileira, no sentido de analisar as particularidades que configuraram e configuram os seus diferentes contextos econômicos, sociais, culturais e políticos. Nesse sentido é que apresentamos este ensaio: na perceptiva de contribuir com os debates que pretendem capturar a historicidade dos contraditórios processos societários que recriam ao mesmo tempo em que mantêm as práticas políticas que exercem o controle sobre a reação da classe trabalhadora diante das profundas desigualdades sociais a que é submetida. Assim, por meio de uma revisão bibliográfica, problematizamos o trato destinado à questão social no período da Primeira República no Brasil (1889-1930), cujas ações do Estado, em linhas gerais, foram marcadas pelo uso da coerção a partir de uma lógica que identificou as manifestações da questão social como "caso de polícia". Nesse sentido, refletimos sobre especificidades que configuraram as condições de reprodução do trabalhador na cidade do Rio de Janeiro, seus movimentos de resistências contra o cenário de exploração da força de trabalho bem como o significado atribuído à questão social e os mecanismos de controle utilizados pelo Estado para garantir a hegemonia de classe que detinha o poder político e econômico. Estas reflexões foram produzidas no curso de uma das disciplinas oferecidas no Programa de Pós-Graduação em Serviço Social da PUC-Rio. A escolha do período histórico elencado está ainda relacionada à prática docente tendo em vista o conteúdo programático ministrado na disciplina intitulada Fundamentos Históricos, Teóricos e Metodológicos do Serviço Social I, obrigatória do primeiro ano da graduação em Serviço Social do UniFOA. A ementa dessa disciplina é composta por temáticas vinculadas à emersão da questão social no Brasil, que desencadeou a explicitação de demandas e a própria criação do Serviço Social na década de 1930 no país. Frente ao exposto, este artigo pode servir de subsídio para os estudantes que se interessam em sistematizar o conteúdo apreendido.

${ }^{1}$ Docente do Curso de Serviço Social do UniFOA.Assistente Social do Tribunal de Justiça do Estado do Rio de Janeiro. Mestre em Serviço Social pela Pontifícia Universidade Católica do Rio de Janeiro. Doutoranda do Programa de Pós graduação em Serviço Social da Pontifícia Universidade Católica do Rio de Janeiro 
Abstract

We believe that the production of the debate about the social question, the object of intervention of social workers, should recognize as a goal, among others, the understanding of the specifics of the historical formation of Brazilian society, in order to analyze the peculiarities that configured and configure their different economic, social, cultural and political contexts. Taking this in consideration, we present this essay: in order to contribute to the debates that aim to capture the historicity of conflicting societal processes that recreate while maintaining political practices that exert control over the reaction of the working class in the face of deep social inequalities that is undergone. Thus, we question the deal for the social question in the period of the First Republic in Brazil (1889-1930), reflecting on specifics that have shaped the conditions of reproduction of the worker in the city of Rio de Janeiro, their movements of resistance against the of exploitation of workforce as well as the meaning given to social issues and the control mechanisms used by the State to ensure the class hegemony which held political and economic power. These reflections were produced in the course of one of the disciplines offered in the Graduate Program at PUC-Rio. The choice of this historical period is related to the teaching practice, in view of the syllabus taught in the course entitled Historical, Theoretical and Methodological Foundations of Social Work I, which is a mandatory one in the first year of the Social Service graduation course at UniFOA. The syllabus for this course consists of topics linked to the emergence of the social question in Brazil, which triggered the explicit demands and the very creation of Social Work in the country, in the 1930s. Based on these, this article can serve as a subsidy for students who are interested in systematizing the content learned.

\section{Keywords:}

Social Question

First Republic

History

\section{Introdução}

Este artigo recorta como temática o significado atribuído à questão social e as respostas construídas para o seu enfrentamento durante o período chamado de Primeira República no Brasil (1889 a 1930), em específico na cidade do Rio de Janeiro.

Compartilhamos da análise de Iamamoto (2008) que postula que a questão social é indissociável da sociabilidade capitalista. Ou seja, a produção da questão social é vinculada às configurações assumidas pelo trabalho e pelo Estado no modo de produção capitalista.

Nessa perspectiva, a autora identifica que a questão social na sociedade burguesa tem sua gênese na seguinte contradição fundamental: o trabalho é coletivo, mas as atividades, as condições e os frutos do trabalho são apropriados de modo privado.

Assim, a questão social é configurada na tensão entre o processo de produção de desigualdades sociais (efeitos da apropriação pri- vada dos meios de produção e dos bens e riquezas) e o processo de resistências e rebeldia do trabalho (que forjam as lutas políticas da classe trabalhadora contra o projeto societário que legitima o capital).

Compartilhamos ainda da ideia que postula que a referida tensão assume especificidades históricas, que são forjadas no bojo das configurações particulares das várias fases do capitalismo (NETTO, 2001).

Nesse sentido, é mister que o estudo acerca do significado da questão social e das respostas construídas para o seu enfrentamento assuma como objetivo compreender tais especificidades da formação histórica da sociedade brasileira, no sentido de analisar as particularidades que configuram os diferentes contextos econômicos, sociais, culturais e políticos.

Consideramos que é por meio de uma perspectiva histórica que nos aproximamos do movimento de uma determinada realidade e, dessa forma, podemos desencadear, no circuito das ideais, a captura da dinâmica das 
relações sociais que configuraram e constroem respostas para a chamada questão social.

Refletimos que a produção de conhecimento acerca das determinações e leis gerais que moldam a sociedade capitalista faz sentido se produzimos mediações, na sua dimensão reflexiva, que sejam capazes de apreender as singularidades históricas. (PONTES, 1997)

Assim, assumindo este desafio, estabelecemos como objetivo ensaiar a produção de um debate acerca do significado atribuído à questão social e as respostas construídas para o seu enfrentamento durante o período da Primeira República no Brasil, em particular na cidade do Rio de Janeiro.

O interesse por esse tempo histórico em especial mantém relação com o desvelamento do pensamento que indica que a questão social fora tratada como caso de polícia (CERQUEIRA FILHO, 1982). E o que justifica o interesse por tal temática?

Assistimos bestializados, na contemporaneidade, práticas políticas que também tratam a questão social como caso de polícia. No próprio debate acadêmico contemporâneo identificamos as análises que explicitam a reedição da criminalização da questão social como um processo que pode ser situado no bojo dos efeitos da reestruturação produtiva do capital levada a cabo no final do século XX. (IAMAMOTO, 2004).

Muitas indagações podem ser construídas a partir de tais análises contemporâneas acerca da criminalização da questão social. Longe de querer explicar o presente por meio da leitura simplista do passado, compartilhamos da ideia de que é relevante desencadear estudos para apreender os heterogêneos e contraditórios processos societários que recriam ao mesmo tempo em que mantêm as práticas políticas, conduzidas em especial pelo Estado, que exercem o controle sobre a reação da classe trabalhadora frente às profundas desigualdades sociais a que é submetida. Desigualdades estas que são forjadas nas metamorfoses processadas na relação capital/trabalho.

Conforme o pensamento de Cerqueira Filho:

A classe social hegemônica, controlando o conjunto da sociedade política (o Estado) e da sociedade civil, combina a coerção e o consenso para obter a acei- tação pelas classes subalternas de um dado tipo de organização econômico-social; portanto organizando politicamente a sociedade, realizando a unidade social

(CERQUEIRA FILHO: 1982, p. 25).

O referido autor postula que é no interior de uma teoria da integração social que é realizado o discurso hegemônico acerca do tratamento da questão social.

Segundo Cerqueira Filho (1982), o pensamento político burguês significa a questão social no interior de uma teoria da integração, convertendo o ideológico em natural na perspectiva de neutralizar os efeitos das lutas de classes, procurando repassar a imagem de harmonia e integração social.

O autor afirma ainda Afirma que, para além das especificidades desse discurso, o fato dele ser útil para os diferentes momentos da própria hegemonia faz com que sejam acionados ora recursos dos aparelhos ideológicos ora os recursos dos aparelhos repressivos do Estado. Pontua que nestes predomina a repressão e naqueles existe a dominância da ideologia. Ressalta que, entretanto, todos os aparelhos do Estado funcionam simultaneamente por meio da repressão e da ideologia.

Cerqueira Filho (1982) analisa que, no plano da prática política (agir), existe uma história irregular acerca dos momentos em que as classes dominantes acionam um ou outro recurso. Entretanto, afirma que existe no plano do discurso político hegemônico (pensar) uma continuidade relativa em lidar com a questão social no interior de uma teoria da integração social.

Assim, esse autor reflete que é o manejo da crise da hegemonia que define o pensar e o agir das classes dominantes no trato da questão social. Afirma que:

(...) nos momentos conjunturais em que uma crise da hegemonia não se configura como viável, o pensar e o agir das classes dominantes tendem a se aproximar, definindo a "questão social" como uma questão eminentemente política, que se resolve na base da conciliação. (...). Isto define a "questão social" como uma questão política. (...). Nos momen- 
tos conjunturais de aguçamento da crise de hegemonia no Brasil, a "questão social" se define como uma questão que deve ser resolvida na base dos aparelhos repressivos do Estado. Isto define a questão social como uma "questão de polícia" que, sem deixar de ser política, passa a ser resolvida com predomínio de uma de suas dimensões, a repressão efetiva, prática. (CERQUEIRA FILHO, 1982, p.28).

Assim, na primeira seção deste ensaio apresentaremos o debate sobre a formação da classe operária nesse período de transição entre o século XIX e XX - destacando as condições de reprodução do trabalhador bem como seus movimentos de resistências na cidade do Rio de Janeiro. A perspectiva é de elucidar feixes de luz para a tensão que produziu a questão social naquele cenário. $\mathrm{Na}$ segunda seção, destacaremos o debate acerca do significado da questão social e dos recursos utilizados pelo Estado para garantir a hegemonia da classe dominante. Por fim, teceremos algumas considerações finais na perspectiva de sistematizar as reflexões processadas.

\section{A tensão na Primeira República: a produção da questão social}

Badaró Mattos (2008) afirma que o Rio de Janeiro, ao longo do século XIX e primeiras décadas do século XX, manteve sua importância como sede do poder no plano político.

No campo econômico, a distribuição de produtos importados e a venda nos portos da produção do café garantiram o crescimento econômico da cidade. $\mathrm{O}$ referido autor cita o crescimento das fortunas dos comerciantes, o surgimento das unidades fabris, a movimentação financeira das casas bancárias como marcas da economia do período.

Assim, a cidade do Rio de Janeiro, na virada do século XIX, experimentou transformações significativas desde os últimos anos do Império, que passaram pela abolição da escravidão e culminaram com a proclamação da república (CARVALHO, 2000).
São citadas as significativas mudanças demográficas no território, marcadas pelo aumento do quantitativo da população. Carvalho (2000) destaca que a abolição lançou o restante da mão de obra escrava no mercado de trabalho livre que estava em formação, aumentando o contingente de subempregados e desempregados. Cita ainda que o êxodo dos trabalhadores das fazendas de café e a imigração portuguesa também contribuíram no processo de crescimento da população. Indica que tal população, na perspectiva étnica e de gênero, era formada, em sua maioria, por negros e por homens.

Badaró Mattos (2008) pontua, entretanto, que a combinação dos dados demográficos com os ocupacionais do então século XIX indica uma diversidade na composição da força de trabalho no período que se estende para o início do século XX.

Esse autor assinala que o processo de proletarização foi, no século XIX, incompleto enquanto o contingente de escravos na cidade foi suficiente para retardar o assalariamento. Esse processo incidiu nas relações de trabalho da Primeira República. O autor afirma, então, que a história da presença do uso do trabalho escravo na cidade determinou a fixação do preço da força de trabalho, incluindo a branca.

Mattos (2008) cita que, após a abolição, o trabalho nas ruas da cidade se manteve como opção de sobrevivência para grande parte de trabalhadores cariocas que não encontravam espaços no mercado formal. Afirma que a abolição da escravatura impôs a mesma condição civil aos negros e brancos. Entretanto, isso não significou uma homogeneidade real da classe operária. Cita ainda a presença de estrangeiros na virada do século e também de mulheres e crianças na composição da força de trabalho.

$\mathrm{O}$ autor indaga sobre "de que forma a experiência da exploração refletia-se nos registros deixados pelos trabalhadores livres". (MATTOS, 2008, p. 55). Para responder a tal questão, recorreu a jornais que seriam porta-vozes de artistas e operários para desenhar a imagem que os que dependiam do salário tinham sobre as suas próprias condições de vida.

Assim, esses veículos de comunicação retrataram, segundo o autor, a longa e exaustiva jornada de trabalho; o trabalho noturno e a 
insalubridade, a inexistência de folgas - nem aos domingos; os constantes acidentes em função das máquinas que intensificavam o ritmo de trabalho; os regulamentos tirânicos (controle de atraso, as revistas, por exemplo).

São explicitados ainda pelo autor os efeitos do crescimento da área urbana em função do incremento populacional. Fala das diferenças do quantitativo de moradores por domicílios nos diferentes bairros da cidade e que a concentração populacional na área central está relacionada à concentração do trabalho e pela dificuldade de locomoção.

Assim, os trabalhadores permaneciam em moradias coletivas (cortiços, estalagem, casas de cômodo, zungus) em função da proximidade do trabalho. A carestia do aluguel (em função da escassez de opção), a insalubridade e precariedade eram vividas pelos trabalhadores e se constituíam como mais uma das faces da exploração a que eram submetidos, reconhecidas por eles como injustiças. Também explicitavam suas indignações em função do contraste entre a cidade civilizada e o modo de vida dos trabalhadores.

$\mathrm{O}$ autor relata que, no início do século $\mathrm{XX}$, as grandes obras dirigidas por Pereira Passos, em nome da saúde pública, demoliram inúmeras construções que eram moradias de trabalhadores, que não foram substituídas. Situa século XX a ocupação dos morros cariocas como alternativa para a classe que trabalhava no centro da cidade. Os trabalhadores cariocas do final do século XIV e início do século XX, enfrentaram, então, a adversidade de acesso, as precárias condições de moradia.

O autor trata da dimensão da exploração vinculada às insalubridades dos locais de trabalho e de moradia e com elas a propagação de doenças letais. A insalubridade não era reclamada apenas pelos trabalhadores das fábricas, mas também pelos trabalhadores do comércio. Assim, a insalubridade se torna responsável pelas epidemias que, desde meados do século XIX, se alastraram na cidade.

Mattos (2008) descreve que os esforços dos higienistas do início do século XX eram de combater a varíola e a febre amarela. Entretanto, afirma que a doença que mais matava os trabalhadores era a tuberculose, aquela vinculada diretamente à insalubridade no trabalho e às péssimas condições de alimentação dos trabalhadores. Afirma que "os militantes do movimento dos trabalhadores sabiam que a questão da saúde pública era uma questão de classe" (MATTOS, 2008, p. 70). Acerca do salário e emprego, o autor revela que os trabalhadores também denunciavam os baixos salários e a carestia a que eram submetidos.

Patto (1999) também retrata bem a espoliação a que estava submetido o trabalhador na Primeira República:

a ausência de leis que garantissem os direitos básicos dos trabalhadores sancionava uma jornada de trabalho fabril esgotante, que podia chegar a 17 horas ininterruptas; a inexistência de férias e de repouso remunerado; salários aviltantes, ainda mais baixos no caso de mulheres e crianças (...) (PATTO, 1999, p. 03).

Badaró Mattos (2008) postula que a miséria era o principal elemento que identificava a experiência homogênea dos proletários. A comparação entre o que o trabalhador recebia e o que ele necessitava para sua sobrevivência ampliava o sentimento de injustiça associado à exploração.

Esse autor analisa que resistência e as primeiras lutas processadas pelos escravos e trabalhadores assalariados urbanos na cidade do Rio de Janeiro na segunda metade do século XIX devem ser reconhecidas para a compreensão da formação da classe trabalhadora do início do século XX.

Antunes (1991) assinala que as primeiras formas de organização da classe operária no final do século XIX foram configuradas pela existência de Associações e Sociedades entre os trabalhadores cujos objetivos estavam vinculados, especialmente, ao auxílio material mútuo. Pontua que, posteriormente, emergiram as Uniões Operárias que, no desenvolvimento da industrialização, passaram a se organizar por ramos de atividades de trabalho e foram precursores dos primeiros sindicatos.

Antunes (1991) também afirma que no início da Primeira República dois Congressos evidenciam a movimentação operária e sindical do período (em 1892 realizou-se o I Congresso Socialista Brasileiro; em 1906 o Primeiro Congresso Operário Brasileiro).

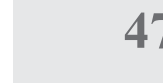

\section{(1)}

列

(1)


Assinala que o movimento operário brasileiro, nesse cenário, foi marcado, essencialmente, pela tendência anarco-sindicalista e pela tendência do socialismo reformista.

Segundo o autor, o fim da primeira Guerra Mundial contribui para o aprofundamento da inflação e a queda do valor dos salários. Carvalho (2000) relata o aumento do custo de vida que a Proclamação da República trouxe. Cita a emissão de dinheiro sem lastro (para aplacar cafeicultores e atender demanda real de moeda para pagamento de salários), a especulação e inflação generalizada, o aumento da importação que marcaram a economia da época.

Tal cenário econômico impulsiona uma onda de greves. O Partido Comunista é fundado em 1922. Carvalho (2000) ainda destaca, em 1925, o início das publicações do jornal "A Classe Operária". Patto (1999) cita que os jornais libertários já registravam os inúmeros episódios de resistências em fábricas: greves, operações- tartarugas, "quebra-quebra" (destruição de matéria prima, máquinas e prédios).

Cerqueira Filho (1982) indica que a questão social aparece, então, no pensamento dominado como relevante. Destaca que os pensadores, publicistas e ativistas elaboraram um pensamento distinto da classe dominante, que priorizava a temática social e a publicização das precárias condições de vida dos pobres e operários. Pontua que, ao contrário, a questão social aparece no discurso dominante como fato excepcional tendo em vista que não aglutinava forças políticas para se impor no pensamento dominante. É nesse sentido que analisa a sentença de que a questão social era caso de polícia.

A guisa de conclusões, esses foram os elementos que se constituíram como tensões que configuraram a questão social. Na próxima seção, refletiremos sobre os recursos utilizados pelo Estado para garantir a hegemonia da classe dominante.

\section{A questão social como caso de polícia}

Chalhoub (2001) analisa que, na passagem do XIX para o XX, para realizar a submissão do liberto, do branco pobre ou do imigrante ao assalariamento, não bastava expropriá-lo. Segundo o autor, além da construção de uma nova ideologia do trabalho foram materializados mecanismos de vigilância e repressão, exercidos por autoridades policiais e judiciárias, para moldar a força de trabalho às necessidades do capital.

Acerca da ideologia do trabalho, o autor sinaliza que

Era necessário que o conceito de trabalho ganhasse uma valoração positiva, articulando-se então com conceitos vizinhos como os de "ordem" e "progresso" para impulsionar o país no sentido do "novo", da "civilização", isto é, no sentido da constituição de uma ordem social burguesa. O conceito de trabalho se erige, então, no princípio regulador da sociedade, conceito este que aos poucos se reveste de roupagem dignificadora e civilizadora. (CHALHOUB, 2001, p. 48)

Assim, o autor identifica que o processo de construção de uma nova ideologia do trabalho ultrapassou a apropriação da "mente" e do "espírito" dos homens livres por meio da disciplinarização do tempo e do espaço estritamente do trabalho. Conforme indica Badaró Mattos (2008) esse processo atingiu também os espaços de sociabilidade e moradia da classe operária, incidindo sobre os padrões de conduta familiar e social.

Chalhoub (2001) postula que tal mecanismo se completou naquele cenário, em específico, por meio do exercício da força e vigilância policial. A noção de "classes perigosas" produziu o estigma sobre aqueles pobres despossuídos, principalmente, do trabalho, e que apresentavam qualquer comportamento que expressasse rebeldia.

Ao serem estigmatizados pelas autoridades policiais e judiciárias como "vadios", promíscuos", "desordeiros" podem se ver arremessados, repentinamente, ao xilindró, onde seriam supostamente "corrigidos" -vale dizer, transformados em trabalhadores, por mais inverossímil que isto possa parecer.(CHALHOUB, 2001, p. 50) 
Nesse sentido, analisando o processo que chamou de desqualificação dos pobres, Pattos (1999) analisa que a república no Brasil nasceu sob a máxima da ordem pública. Pontua que os intelectuais e os militares, herdeiros das concepções evolucionistas que naturalizaram o social, defendiam a tese do progresso ordeiro, forjando um caráter nada revolucionário ao movimento republicano.

Ao contrário, o horror aos movimentos operários sinalizava a frequência com que a repressão para conter as reações e as rebeldias dos trabalhadores.

A frase "questão social como caso de polícia", dita pelo então Presidente da República Washington Luís, sintetiza o "pensar e o "agir" do Estado no período.

As sucessivas vezes em que foi decretado Estado de Sítio representa esse processo de repressão contra a oposição aos interesses hegemônicos (PATTOS, 1999).

Carvalho (2000) destaca ainda a proibição da capoeira (que foi incluída como crime na revisão do Código Penal de 1890), a expulsão dos anarquistas estrangeiros, a punição ao jogo do bicho, a destruição dos cortiços, as leis de obrigatoriedade das vacinas como mecanismos que também configuraram o controle repressor sobre os pobres.

Pattos (1999) sinaliza que, quando a desarticulada massa ameaçava se transformar em classe social, a piedosa simpatia pelos "deserdados da fortuna", pelos "humildes", começou a se converter em práticas repressivas. Cabia à polícia deter o protesto proletário e ainda punir toda sorte de comportamentos "desordeiros".

A autora cita as mudanças no Código Penal, que trataram de criminalizar comportamentos dos pobres livres cujo trabalho era desnecessário. Pontua que a "embriagues", a "desordem" e a "vadiagem" foram motivos da maioria das prisões efetuadas no período. Assinala que bastava ser pobre, não-branco, desempregado ou insubmisso para estar sob a suspeita da polícia. Destaca os termos utilizados nos relatórios policiais para classificar os desempregados e subempregados: "vadios", "incansáveis", "parasitas", "sanguessugas", "desordeiros". Analisa que a atenção para esses termos que classificavam pessoas e comportamentos contribui no processo de desve- lamento dos mecanismos de controle social engendrados na sociedade brasileira.

No interior de um confronto de classes absolutamente desigual, o que predominou foram os punhos cerrados da polícia, para quem, no Brasil, as leis nunca tiveram muita importância e o abuso de poder sempre foi a regra (...) as operações policiais na primeira república não pretendiam outra coisa senão excluir e, sempre que possível, exterminar os que ameaçavam a paz da burguesia ou o projeto eugênico de progresso." (PATTOS, 1999, p. 11)

Assim, Cerqueira Filho (1982) entende que a questão social não era uma questão legal em função da sua ilegitimidade política. Desta forma, deveria ser tratada no interior dos aparelhos repressivos do Estado.

$\mathrm{O}$ autor analisa que a questão social, ao ser tratada como caso de polícia, foi inscrita no campo da criminalidade e da desordem. Outrossim, as reações da classe dominada não faziam o eco na agenda política das classes dominantes tendo em vista que a industrialização, naquele período, ainda estava em segundo plano na estrutura de produção brasileira. Fazia sentido, então, desconsiderar a existência da questão social, desqualificar as reivindicações e rebeldias operárias e inscrevê-las no campo do crime.

Conforme escreve Cerqueira Filho, "os problemas sociais tratados pela polícia nunca existiram porque eram passíveis de serem exterminados à bala" (1982, p. 61).

Desta forma, a questão social não aparece como preocupação do discurso dominante naquele período. Monarquistas, jacobinos (liberais), ou militares (grupos que compunham a correlação de forças no período) tangem seus interesses para outras questões vinculadas ao poder político e econômico (CERQUEIRA, 1982).

A questão social permanecera como marginal no discurso dominante, mas como elemento central no discurso da classe operária.

Essa tensão, constante durante toda primeira república, entre o existente como problema, mas não como questão, acaba por dar lugar à contradição, ao nível 
do pensamento dominante, quando trata a questão social como caso de polícia, que nada mais são que um retorno daquilo que se quer reprimido, recalcado: os conflitos entre capital-trabalho. (CERQUEIRA, 1982, p. 68).

Negar (no plano do pensar) e reprimir (no pano da ação) a questão social se constituíram como mecanismos para escamotear os conflitos e lutas de classes. Tal movimentação foi importante para sustentar a expansão do capitalismo no Brasil nos primeiros passos da formação da República.

\section{Considerações Finais}

Perseguimos, neste ensaio, o objetivo de refletir sobre o significado atribuído à questão social e as respostas construídas para o seu enfrentamento durante o período da Primeira República no Brasil. Destacamos as tensões que produziram a questão social e os recursos utilizados pelo Estado frente à mesma.

A proclamação da República foi desenhada pela elite brasileira a partir da disputa entre as oligarquias tradicionais (que ocupavam o poder político) e as novas oligarquias dos fazendeiros de café de São Paulo (detentoras do poder econômico), sem a participação efetiva de setores populares da sociedade.

Tal período histórico, segundo os autores estudados, é marcado pelos impactos iniciais da transição do modo de produção que começou a se processar naquele período: a Primeira
República não foi industrial, mas foi marcada pelo crescimento da indústria.

As diferentes relações de produções engendram mutações no processo de exploração dos trabalhadores - que começa a se perceber enquanto classe. $\mathrm{Na}$ cidade, liberto, pobre branco ou imigrante são submetidos a condições desumanas de trabalho e de vida. As condições de sua reprodução material e espiritual inviabilizavam sua própria existência. Assim, a república, nos seus primeiros anos, foi marcada também pela formação e organização da classe operária, sendo palco de reações e rebeldias, principalmente, levadas a cabo pelos anarquistas e socialistas-reformistas.

Entretanto, no processo de publicização da questão social, não se acumula forças políticas para que fosse reconhecida como legítima, sendo tratada como caso de polícia. As oligarquias agrárias, que detinham o poder econômico e político, significaram a questão social como crime que necessitava de punição e repressão.

A necessidade de que a classe operária absorvesse uma nova ideologia que positivasse o trabalho e o assalariamento para que sua força de trabalho atendesse aos interesses do capital, utilizou recursos ideológicos, que incidiram no âmbito do trabalho e da vida do trabalhador para moldar o seu comportamento.

Entretanto, foi por meio da vigilância e da repressão, exercidos especialmente por autoridades policiais e judiciárias, que o controle se processou. Por quê? A massa desordenada de trabalhadores ousou se transformar em classe. 


\section{Referências Bibliográficas}

1. ANTUNES, Ricardo. O que é sindicalismo. São Paulo: Editora Brasiliense, 1991.

2. CARVALHO, José Murilo. Os bestializados: $O$ Rio de Janeiro e a República que não foi. São Paulo: Companhia das Letras, 2000.

3. CHALHOUB, Sidney. Trabalho, Lar e Botequim: cotidiano dos trabalhadores no Rio de Janeiro da belle époque. São Paulo: editora da UNICAMP, 2001.

4. CERQUEIRA FILHO, Gisálio. A "Questão Social" no Brasil: crítica ao discurso político. Rio de Janeiro: Civilização Brasileira, 1982.

5. IAMAMOTO, Marilda. Questão Social, Família e Juventude: Desafios do Trabalho do Assistente Social na Área Sócio Jurídica. In: LEAL, M. MATOS, M e SAlES, M (org). Política Social, Família e Juventude: uma questão de direitos. São Paulo: Cortez, 2004.
6. Serviço Social em Tempo de

Capital Fetiche: capital financeiro, trabalho e questão social. São Paulo: Cortez, 2008

7. MATTOS, Marcelo Badaró Escravizados e Livres: experiências comuns na formação da classe trabalhadora carioca. Rio de Janeiro: Bom Texto, 2008

8. NETTO, José Paulo. Cinco Notas a Propósito da "Questão Social". Temporalis. Rio de Janeiro: ABEPSS, Ano II, nº 03, Jan. a Jun., 2001.

9. PATTOS, Maria Helena Souza. Estado, Ciência e política na Primeira República: a desqualificação dos pobres. Estudos Avançados. Vol 13 n 35. São Paulo: Jan.। Abr. 1999. Disponível em: <http: // www. scielo.br >. Acesso em 20 de maio de 2011.

10. PONTES, Reinaldo Nobre. Mediação e Serviço Social. São Paulo: Cortez, 1997. 